\title{
Doctors and voluntary services
}

\author{
Ben Fong *, MPH(Syd), FHKAM (Community Medicine) \\ Division of Science, Engineering and Health Studies, College of Professional and Continuing Education, \\ The Hong Kong Polytechnic University, Hong Kong \\ *Corresponding author: byffong@gmail.com
}

Hong Kong Med J 2020;26:171-3

https://doi.org/10.12809/hkmj205097

Volunteer work is done with the wish to help people, commonly arising from one's passion, drive, sense of social responsibility, and dedication. Society is in need of volunteer services for health education and promotion, be they health seminars, exhibitions, patient self-help groups, or one-toone patient counselling services. Doctors are in a privileged position to collaborate with other allied health professionals in an interdisciplinary team, so their service scope could be even broader and more comprehensive, involving not only the general public but also patients, their family members, and their caregivers. Doctors are looked upon as social models, at times even the untouchable citizens. They are expected to have very high, if not the highest, professional and ethical standards, as well as being competent, just, honest, responsible, obliging, caring, and approachable. Many doctors choose to contribute to community services in various roles and responsibilities by taking up honorary positions in non-governmental organisations, public bodies, government boards and committees, educational institutions, non-profit-making health organisations, and professional associations.

Many medical professionals serve outside their working hours in emergency, rescue, and first-aid forces, including the Government Flying Service, ${ }^{1,2}$ the Auxiliary Medical Service, ${ }^{3}$ the Red Cross, and the St John Ambulance service. These volunteers provide pre-hospital trauma and emergency treatment and advanced life support, and share their professional knowledge, skills and experience to lay volunteers with the objective to improve the standards and skill set of the entire volunteer force. Such involvement of doctors reduces the need for case transfers to hospital accident and emergency departments, particularly at large public events. Doctors, like all volunteer members, are "dedicated and committed to the worthwhile cause of saving lives and relieving pain of the injured, serving all walks of life irrespective of their race, age, or occupation". ${ }^{3}$ Moreover, doctors are often called upon to volunteer their services, both at home and abroad, at times of major incidents, including natural disasters such as Typhoon Mangkhut in 2018, or the current coronavirus disease 2019 (COVID-19) pandemic. These medical professionals and team volunteers are highly regarded for contributing their valuable time and professional services to the needed and to save lives in such potentially dangerous environments.

Personal characteristics, such as religion, marital status, having a family, and home stress, as well as professional characteristics that reflect autonomy and workload, such as type of practice, work location, working hours, and professional training, affect the amount of time a doctor dedicates to voluntary services. ${ }^{4}$ The youngest and oldest medical professionals are less likely to serve as volunteers, but those with children are more willing to do so. In addition, family doctors and those practising in the rural areas have shown a more personal and lifelong commitment to the society and are more ready in responding to strong community expectations of volunteering. ${ }^{4}$ Some doctors are motivated to provide volunteer services to others in trying to develop and maintain their own positive identities. Such identities are associated with the doctor's desires to be perceived as a good doctor by patients and colleagues. Volunteerism also creates meaning and purpose in one's life through personal development and fostering social support from the positive experience outside normal working lives. ${ }^{5}$ There are many benefits of volunteering, including enhanced physical and psychosocial wellness, increasing self-confidence, having a sense of purpose and fulfilment in life, professional and social networking, career development, etc. ${ }^{6}$

No matter what, volunteer doctors should commit with the highest respect, dignity, and equality to provide genuine assistance untainted by personal ambition or pecuniary gains. Such obligation has practical, professional, and philosophical implications in all aspects of medical volunteerism. ${ }^{7}$ At the same time, medical students and junior doctors are very much inspired to serve in voluntary community healthcare works by a dedicated team of medical professionals with a united vision. ${ }^{8}$ They will become a different type of doctors, who do not regard medical service as merely a profession that mainly benefits themselves, but who also understand and respond to the needs of the society, particularly the underprivileged and minority communities. ${ }^{9}$ The Hong Kong Medical Journal has previously interviewed a number of outstanding healthcare professionals to recognise 
their contributions to the society, ${ }^{2}$ and the scope of their service recipients is very broad-ranging from children, ${ }^{10,11}$ the vulnerable groups, ${ }^{12}$ the general public, ${ }^{13-15}$ practising physicians, ${ }^{16}$ and patients in need of rehabilitation. ${ }^{17,18}$ They should be our exemplary models to learn from.

Doctors are working as volunteers in many parts of the world and under the auspices of a variety of organisations. The services have been shown to have far-reaching benefits to the individuals and the host organisations, regions, and countries. The doctors will broaden their skills base, promote positive values of volunteerism, contribute to the health, well-being and public health services and social care to those being served. However, the scale and scope of such activity is normally not well documented, and the arrangement of the involvement are mostly informal. ${ }^{19}$ A study has recommended to address the need for volunteer preparation and to evaluate the practice to maximise the benefits of volunteering, reduce the risk of harm and, optimise learning and accountability, through formal development, standardisation, coordination, and professionalisation. There are also issues of lacking the structure and framework for debriefing, and evaluation of the services rendered and validation of outcomes, especially in the context of ethical quality. Thus, written official guidance on the best practice in voluntary services should be developed to enhance the benefits while avoiding harm, like medical errors. ${ }^{20}$ The guidelines should address the areas of the principles of mission, partnership, preparation, reflection, supports, sustainability, and evaluation in medical volunteerism. ${ }^{21}$

Volunteer doctors are devoted and enjoy serving people in need of assistance during good times and difficult situations arising from daily activities and unexpected emergency calls of the nature. Giving back to the community allows doctors to experience the joyful encounters and excitement with non-financial rewards and satisfaction from serving others and meeting the changing challenges and needs of the world outside their professional domain. To promote such invaluable services and to maximise the contribution of volunteers, a structural approach to facilitate and further develop a practical framework of medical volunteerism, particularly in response to disastrous situations, is highly desirable. Formalisation of medical volunteers with effective management support and positive publicity will attract many more doctors to the services, drawing the "untapped" professional resources to the social capital. The government should consider the inclusion of medical volunteerism in the emergency response plan and work with medical organisations to further enhance the impacts of doctors in their role as volunteers.

\section{Author contributions}

The author contributed to the concept of the study, analysis or interpretation of the data, drafting of the manuscript, and critical revision of the manuscript for important intellectual content. The author had contributed to the manuscript, approved the final version for publication, and takes responsibility for its accuracy and integrity.

\section{Conflicts of interest}

The author has disclosed no conflicts of interest.

\section{Funding/support}

This editorial received no specific grant from any funding agency in the public, commercial, or not-for-profit sectors.

\section{References}

1. Government Flying Service. Service \& operation. Available from: https://www.gfs.gov.hk/eng/service.htm. Accessed 19 Apr 2020.

2. Tsui M, Chan B. Part of a larger whole: serving in the Government Flying Service. An interview with Dr Ralph Cheung. Hong Kong Med J 2018;24:644-5.

3. Auxiliary Medical Service. Available from: https://www. ams.gov.hk/eng/main.htm. Accessed 19 Apr 2020.

4. Frank E, Breyan J, Elon LK. Pro bono work and nonmedical volunteerism among U.S. women physicians. J Womens Health (Larchmt) 2003;12:589-98.

5. Reeser JC, Berg RL, Rhea D, Willick S. Motivation and satisfaction among polyclinic volunteers at the 2002 Winter Olympic and Paralympic Games. Br J Sports Med 2005;39:e20.

6. Meszaros L. Physician volunteerism: The surprising benefits for doctors who do it. Available from: https://www. mdlinx.com/internal-medicine/article/2841. Accessed 19 Apr 2020.

7. Bauer I. More harm than good? The questionable ethics of medical volunteering and international student placements. Trop Dis Travel Med Vaccines 2017;3:5.

8. Favara DM, Makin L. Chesed Children's Clinic: a nonprofit, paediatric primary care outreach clinic in the Eastern Cape created by junior doctors and volunteers. S Afr Med J 2013;103:356-7.

9. Tungsubutra K. Primary health care and volunteer health workers - an experiment in northeastern Thailand. JOICFP Rev 1983;(6):32-6.

10. Chan WW, Lo AT, Wong K. Putting a smile on children's faces: an interview with Dr Bernard Sik-kuen Chow. Hong Kong Med J 2018;24:87-9.

11. Lam C, Cheuk N, Yeung C. Healing hearts in paediatrics: an interview with Dr Adolphus Chau. Hong Kong Med J 2019;25:416-8.

12. Yeung $\mathrm{CH}$, Cheuk NK. Breaking down frontiers through medical humanitarianism: an interview with Prof Emily Chan. Hong Kong Med J 2018;24:208-11.

13. Chan B, Cheng HE, Lo MT, So N. Clinician and teacher, sportsman and coach: an interview with Dr Henry Lam. Hong Kong Med J 2019;25:260-1.

14. Chan JH, Kwok HH, Li VS. The secret to disease-free living: a wholefood plant-based diet. An interview with Dr Irene Lo. Hong Kong Med J 2018;24:432-3.

15. Xue W, Leung BPH. Duty and excellence-an interview 
with Dr Kin-hung Lee. Hong Kong Med J 2018;24:543-5.

16. Chan JH, Kwok HH, Li VS. Professor Kwok-yung Yuen: embracing life with a beginner's heart. Hong Kong Med J 2019;25:83-5.

17. Tsui M, Cheung M, Chan C. A pioneer in comprehensive rehabilitation: an interview with Professor Chetwyn Chan. Hong Kong Med J 2019;25:170-1.

18. Yau R, Lau N. World volunteer and carer for bones and minds: an interview with Dr Chi-wai Chan. Hong Kong Med J 2019;25:501-2.
19. British Medical Association. Doctors as volunteers. 7 December 2018. Available from: https://archive.bma.org. uk/collective-voice/influence/international/global-health/ doctors-as-volunteers. Accessed 30 Apr 2020.

20. Eadsforth H. Professionalisation of international medical volunteer work to maintain ethical standards: a qualitative study exploring the experience of volunteer doctors in relation to UK policy. Med Sci (Basel) 2019;7(1). pii: E9.

21. Stone GS, Olson KR. The ethics of medical volunteerism. Med Clin North Am 2016;100:237-46. 